\title{
Antín / Cortázar: cruces y destiempos entre la escritura y el cine
}

\section{Zangrandi, Marcos [ver currículum del autor, docente de la Facultad de Diseño y Comunicación]}

\section{Resumen:}

Este artículo estudia la relación de colaboración mutua que mantuvieron el cineasta Manuel Antín y el narrador Julio Cortázar entre 1963 y 1965.

Durante ese lapso, ambos trabajaron en la escritura de los guiones de los filmes Circe e Intimidad de los parques. El vínculo que los dos construyeron en sus encuentros personales y a través de cartas pone de manifiesto un modo de labor inédito en el cine argentino alrededor de la escritura cinematográfica. Asimismo, la relación entre estas dos figuras da cuenta de un cambio en los vínculos entre el cine y de la literatura dentro del campo cultural. En este sentido, durante los años 1960 uno y otro espacio trazan lazos sinérgicos que potencian su dimensión sociocultural.

Palabras clave:

cine argentino - literatura argentina - Manuel Antín - Julio Cortázar - escritura - colaboración.

$\left(^{*}\right)$ Doctor en Ciencias Sociales (UBA). Magíster en Comunicación y Cultura (UBA). Licenciado en Comunicación Social (UNC). Becario posdoctoral de CONICET. Ha dictado clases en la Universidad Nacional de Cuyo, en la Universidad de Palermo y la Universidad del Cine (FUC).

Manuel Antín inició su trabajo como cineasta transponiendo tres relatos de Julio Cortázar: La cifra impar (1961), sobre el cuento "Cartas de mamá"; Circe (1963), sobre el relato homónimo e Intimidad de los parques (1964), sobre "El ídolo de las Cícladas" y "La continuidad de los parques"1. La forma en que Antín y Cortázar trabajaron en ellas era novedosa. No se correspondía con las numerosas adaptaciones de novelas o de cuentos sin
Cuadernos del Centro de Estudios de Diseño y Comunicación № 61

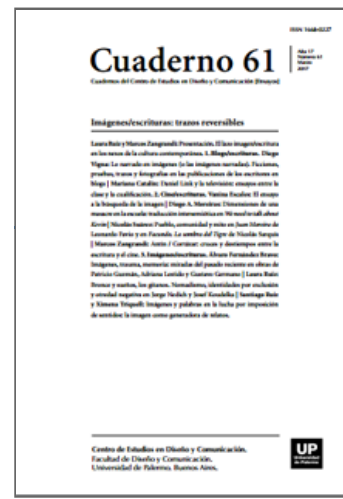

descargar PDF ver índice de la publicación

Ver todos los libros de la publicación

compartir en Facebook

Commons Atribución-NoComercial-

Compartirlgual 4.0 Internacional 
participación directa del escritor que hasta mitad de siglo se habían realizado en el cine argentino, como el clásico La guerra gaucha (1942), en base a la novela de Leopoldo Lugones, o las versiones para la pantalla grande de las narraciones de Hugo Wast, como La casa de los cuervos (1941). Tampoco esa modalidad podía ser equiparada con la participación profesionalizada en los libros cinematográficos por parte de algunos escritores reconocidos (entre otros, Manzi, César Tiempo, Enrique Santos Discépolo y Alberto Vaccarezza)2.

La dupla Antín / Cortázar, en cambio, se propuso un trabajo de escritura en colaboración distinto de la simple adaptación, y de cual había escasos antecedentes claros y sostenidos3.

Más aún, la asociación entre ambos pone de manifiesto una serie de transformaciones para el cine argentino. Por un lado, se trata de una alteración y una erosión de los límites de los roles del director, del escritor y del guionista tal como estaban planteados hasta la década de 1950. Ello no implicaba una pérdida de roles o de espacios, sino que, por el contrario, su relación potenció y amplió la dimensión de las figuras, como en esos años comenzó a suceder con otras duplas, como las de Beatriz Guido / Leopoldo Torre Nilsson, Fernando Ayala / David Viñas y José Martínez Suárez / David Viñas. Por otro lado -y este aspecto es fundamental- el espacio de convergencia que favoreció este tipo de imbricación fue el de la labor de la escritura.

La sola idea de escribir de a pares propicia incomodidades. Como apuntan Peeters y Lafon (2008) la escritura en colaboración ha sido asiduamente evitada por los cánones de la cultura occidental, bajo la sombra de una "ideología del yo". Los trabajos realizados en conjunto cuestionan, en este sentido, una sentencia tácita: que la autoría es única y que, incluso cuando la labor se ha realizado por dos o más, uno de ellos tiene mayor reconocimiento que los otros. Distintos factores histórico-culturales empujarían así a que uno de los nombres prevaleciera (en mayor o en menor medida) sobre el otro, velando la tarea en conjunto. Pero existen muchos ejemplos de pares de escritores que produjeron obras notables y que impugnan ese dogma: Bioy Casares y Borges, Engels y Marx, Deleuze y Guattari, Dumas y Maquet, Conrad y Ford Madox Ford, entre otros.

Esta perspectiva se vuelve ineludible cuando se considera el campo del cine, espacio de aportes múltiples, al que no puede pensárselo sino en el trabajo grupal, aunque con roles jerarquizados y diferenciados en su formato industrial (productor, director, montajista, guionista, dialoguista entre otros). En la mitad del siglo XX aparecen replanteamientos en este tipo de trabajo compartimentado. Ciertamente, en esta época aparece una fuerte "literaturización" del cine, por efecto de la centralidad y prestigio que adquirieron algunos cineastas (Welles, Rossellini, Wilder, Renoir) y por la influencia de la crítica cinematográfica de esta época, en particular de la francesa. Bajo este punto de vista, la figura del director, empujado por "la política de autor" y por la idea del cine como escritura, adquirió un atractivo contorno, en tanto podía convertirse en un autor, con una posición cercana a la de un escritor (Stam, 2001). Ténganse en cuenta la conocida figura propuesta por el crítico Alexandre Astruc, cuando en se refería a la cámara como una pluma o las observaciones de François Truffaut y Andre Bazin (con sus diferencias) sobre la capacidad del director para imponer una individualidad y un estilo personal a su cine (Faulstich y Korte, 1995).

La "política del autor", en su vocación por acercar y a la vez diversificar los mundos de la literatura y del cine, implicaba necesariamente duplicaciones, ampliaciones y redimensionamientos de los roles, a cambio de las habilidades técnicas del cine industrial. Las conocidas duplas de trabajo del director Alain Resnais con los escritores Marguerite Duras (Hiroshima mon amour, 1959) y Alain Robbe-Grillet (El año pasado en Marienbad, 1961) se volvieron ejemplares de estos puntos de convergencia4. Más aún, durante los años 1960 varios 
cineastas, apuntalados o no por escritores de renombre, alcanzan un estatus prestigioso en la cultura a partir de un cine de estilo personal equiparable al de los escritores, como Jean-Luc Godard, Michelangelo Antonioni e Ingmar Bergman.

Fracturas y giros en el cine argentino

En 1955, luego del golpe de Estado que derrocó a Juan D. Perón, el cine argentino se encontraba en una situación de parálisis inédita. A la crisis que ya había hundido a grandes sellos cinematográficos (Lumiton, EFA, Pampa Film, Artistas Asociados Argentinos), se sumó el desguace del sistema de apoyo estatal por parte del gobierno militar (Peña, 2012).

Los años 1956 y 1957 fueron, por ende, de bajísima producción, mientras se discutía una nueva ley que reformularía las reglas del juego. En este contexto se abrió un fuerte debate entre productores, directores, exhibidores y trabajadores para poner en marcha el cine.

Entre esas intervenciones, se destacaba una demanda de políticas que fomentaran filmes de mayor calidad artística y técnica. Para una nueva camada de cineastas y productores de entonces, el cine argentino era una máquina comercial, repetitiva y vacía5. No había mayor atractivo artístico en ella, ni posibilidades de una renovación que transformara sus esquemas de producción y de narración. "No se miraba cine argentino" recuerda Manuel Antín respecto de los años 1950- "Yo iba mucho al cine, pero no iba a ver cine nacional.

Nunca me interesó el cine argentino porque siempre creí que era un cine sin inspiración.

Eran productos comerciales en todo sentido, salvo excepciones" (Antín, comunicación personal [29 de setiembre de 2014]). Leopoldo Torre Nilsson fue una voz medular en los debates de la nueva ley. Este director -que venía de la industria pero estaba decidido a promover otro tipo de realizaciones- impulsaba la posibilidad de un "cine de expresión" de carácter personal como alternativa del cine industrial, propuesta que puede leerse como la introducción de la política de autores en el panorama local6.

Finalmente, el decreto-ley 62/57 fue aprobado a principios de 1957. Mediante esta norma se establecía una política de subsidios y créditos para la producción cinematográfica, un organismo administrativo (el Instituto Nacional de Cinematografía) y premios anuales que tenían como fin estimular filmes de calidad. La ley indicaba también la creación de un Centro Experimental Cinematográfico y una Cinemateca Nacional (Peña, 2012). La ley (que es la misma que sigue rigiendo hoy, con modificaciones) fue implementada fragmentariamente y con muchos obstáculos de acuerdo con los intereses de los actores involucrados.

El aspecto más importante fue que el cine era considerado por primera vez no sólo como un producto industrial o del espectáculo, sino también un bien cultural. Era un giro que institucionalizaba una nueva forma de entender el cine argentino y de acercarlo, con sus especificidades y pluralidades, a la cultura letrada.

La nueva normativa es el marco de un proceso de transformaciones que ya estaba presente en el cine argentino. En efecto, como señala Claudio España (1997) durante la década de 1950 son visibles algunas fracturas en los modos de representación y en la narración del cine genérico, que dan cuenta del agotamiento de una forma clásica de mostrar y de contar que había funcionado desde la conformación de la industria cinematográfica a principios de los años 1930. Esas marcas, a la manera de una "fractura", podían verse en la 
aparición repetida del flashbacks complejos y de saltos temporales, de músicas disfuncionales, de encuadres no convencionales y de nuevos rostros7. Rasgos que daban cuenta de un cine que incorporaba tenuemente aspectos renovadores (la enunciación sobre el enunciado, la representación sobre lo representado, las marcas de la escritura sobre lo escrito, la ruptura de la mímesis), todos ellos índices de la expresión moderna (Sánchez Noriega, 2000). Era la puerta hacia la renovación del cine argentino, que se consumaría en la década de 1960 con directores más audaces como José Martínez Suárez, Ricardo Alventosa, David Kohon, Rodolfo Kuhn, Enrique Dawi, Simón Feldman y Leonardo Favio (Peña, 2003).

\section{Dos espacios que se cruzan}

Desde muy joven, Manuel Antín tenía una vocación clara: quería convertirse en escritor.

De hecho, antes de comenzar a filmar ya había publicado tres poemarios con fondos propios8.

Según su recuerdo, "mi vocación era la literatura y el teatro, ya había estrenado dos obras de teatro. Mi fantasía era ser autor teatral, novelista, cuentista o poeta..." (Peña, 2003, p. 31). Lector voraz, en 1956 encontró en la biblioteca de un amigo un ejemplar de Bestiario de Julio Cortázar, por entonces un escritor todavía poco conocido fuera del circuito literario argentino (Canoso, 1995; Peña, 2003)9. La lectura del libro significó un vuelco en la carrera de Antín. En esas narraciones, con su desestructuración del tiempo, sus apuestas al género fantástico y sus juegos narrativos, encontró aquello que él hubiera querido escribir: "Era como si al mundo que yo tenía, él le hubiera puesto letra. Y me encontraba con sus historias que me parecían las mías (...) Descubrí que era el escritor que yo no era; 'mi otro yo escritor'” (Canoso, 1995, p. 14). Pero por sobre todo, en Cortázar descubrió la semilla de su trabajo cinematográfico. Una noche, en un café, les relató a unos amigos "Cartas de mamá" (incluido en Las armas secretas, 1959) como si fuera no un cuento sino una película que había visto recientemente. Al final de su narración, Antín reveló la verdad. Había sido tan elocuente que, de inmediato, los dos amigos, Axel Harding y Raúl Schön, le propusieron convertir ese relato en una película, ofreciéndose ellos mismos como productores (Canoso, 1995). Este fue el inicio de la carrera como director de Manuel Antín. Nótese, por fuera de la anécdota, que su iniciativa se construye a partir de un relato literario y de una vocación marcadamente intelectual. Luego, que la narrativa que lo fascina posee rasgos novedosos y, en este sentido, no es sólo el recurso fantástico el que quiere llevar a la pantalla grande sino su costado modernizador. Finalmente, que Antín poseía una interesante habilidad de hacer pasar por cine un texto literario.

Por otra parte, el joven director ensaya, en ese momento, un recurso que más adelante implementaría en la labor con el mismo Cortázar: la apropiación de la narración y el relato oral (cuando no el dictar un relato) a la manera de ensayo de la escritura, de una preescritura.

El mismo Antín define la tarea cinematográfica con la imagen de quien dicta: Para mí dirigir una película es como dictar una carta. Se le dice al iluminador: ‘Quisiera este cuadro con esta luz' (...) Cada uno hace su trabajo, y el director es alguien que dicta, el que coordina, el que dirige, el que le da entrada a cada uno de los instrumentos en el concierto.

(Canoso, 1995, p. 11) Tan pronunciada era esta impronta intelectual para la nueva generación de cineastas que no les preocupaba tener conocimientos técnicos para filmar. Según el propio Antín, "en esa época nosotros filmábamos con equipos del sindicato (SICA). Los únicos que no sabían de cine eran los directores. Los demás 
eran los que fabricaban la película. lluminadores, cameraman, yo no sé ni cargar una cámara" (Antín, comunicación personal [29 de setiembre de 2014])10. Ello da cuenta de la necesidad del nuevo cine de prestigiarse aspirando a tener un estatuto semejante al de la cultura letrada. No se cargaban cámaras ni reflectores, pero sí era imperioso para un cineasta, en cambio, poseer inquietudes intelectuales: leer, ser cinéfilo, escribir -escribir a través del cine-. Hay cierto gesto de exclusivismo, indudablemente, aunque ello no representaba el desprecio directo por los grandes públicos, sino llevar la expresión estética hacia otro nivel, despegado del simple entretenimiento y de la diégesis clásica. "Lo que se nota en mis películas" -comenta al respecto Antín- "y es el motivo por el cual mis películas nunca fueron un éxito, es que no se pueden entender profundamente.

Porque el espectador no pone su inteligencia en el cine. Pone su sensibilidad" (Antín, comunicación personal [29 de setiembre de 2014]).

Julio Cortázar coincidía en este proyecto estético que reubicaba el estatuto del cine, y así se lo expresaba a Antín en 1964: Quizá fue necesario pasar por las etapas de La cifra [impar] y Los venerables [todos] para que tu lenguaje alcanzara ese punto indefinible pero que conozco bien, en el que una obra difícil y aristocrática (en el sentido más hondo del término) consigue sin embargo incidir profundamente en el espectador. Yo creo que en eso está el casi milagro de un Beckett en el teatro y de un Alain Resnais en el cine. (...) Esa distancia, que en otros creadores se convierte en una valla insalvable, y los condena a no ser comprendidos hasta mucho después de muertos, queda sin embargo anulada por ese misterioso ingrediente que conecta y comunica una experiencia estética.

(Cortázar, 2012, pp. 475-476)11 Es notable que Cortázar utilice el término "aristocrática" para referirse al lazo creado entre el cineasta y su público. Es el mismo del que se valía Victoria Ocampo cuando, más de una vez, reiteró el ideario de aristocracia cultural (y no se refería al abolengo o a la fracción social) conformada por el circuito de escritores y lectores apartados de las contingencias políticas o sociales (Queirolo, 2009), aspecto que ayudaba a sostener la autonomía de la literatura en el espacio social12. Esto no implica que Cortázar mantuviera a mediados de la década de 1960 los ideales estético-culturales de la directora de la revista Sur, por entonces residuales, pero sí, como se destaca en la cita, que guardaba cierto eco de ella transpuesta a determinado cine. Esto es, el narrador daba a entender que algunas expresiones propias de esta época propiciaban y articulaban zonas privilegiadas de complejidad y de modernización estética (características de su literatura), y que, acaso, ellas podían ser accesibles a un público relativamente amplio (algo que, en realidad, no sucedió en el caso de Antín)13.

Con o sin esa posibilidad, el argumento de Cortázar consolidaba el nuevo espacio del cine dentro del campo de la cultura.

Julio Cortázar era cinéfilo y admiraba profundamente a algunos directores europeos (en particular a Luis Buñuel, quien estuvo a punto de filmar uno de sus cuentos)14. Veía en el cine atractivas posibilidades para sus narraciones, de acuerdo a la difusión y el impacto sociocultural que tenía la pantalla grande. El cine se había convertido en una expresión que adquiría calidad autoral y se abría, a la vez, hacia el plano de lo masivo. Como lo señalaba Antín, a principios de los años 1960, "la literatura tenía alguna página en los diarios de los domingos. El cine, tres o cuatro todos los días" (Antín, comunicación personal [29 de setiembre de 2014]). Por esta razón, cuando Antín le propuso en marzo de 1961 comprar uno de sus cuentos para adaptarlo, aun cuando fuese un 
cineasta totalmente novato, Julio Cortázar aceptó sin dudarlo. Más aún, luego de la experiencia de La cifra impar, quedó tan satisfecho que le propuso filmar otras de sus narraciones, como los relatos "Bruja", "El río", "Los buenos servicios" y la novela Divertimento (por entonces inédita), como se detalla en cartas de junio y julio de 1962 (Canoso, 1995, pp. 22-28), proyectos que nunca se llevaron a cabo15. Entusiasmo que habla menos de un escritor que "cede" sus obras para ser adaptadas (propuesta que apuntalaría la línea de una literatura como fundamento y el cine como su proyección), que de la apertura hacia un nuevo plano capaz de brindar mayores posibilidades expresivas a sus cuentos que los que ofrecía la tinta y el papel.

Antín ansiaba convertirse en un escritor, pero no hallaba la forma precisa de escribir aquello que tenía en mente. Cortázar estaba fascinado por las potencialidades que ofrecía el cine. Antín recuerda el vínculo de complementariedad entre ambos: En alguna oportunidad él me preguntó por qué yo filmaba sus cuentos. Y le dije "Porque vos tenés lo que yo quisiera tener para escribir", a lo que él me respondió "Ahora me das una linda idea, ya que yo quisiera hacer lo que vos hacés". Yo amaba la literatura y me hubiera gustado escribir como él; él adoraba el cine y le hubiera gustado ser director. Se dio entre nosotros una de esas historias borgeanas -o por qué no cortazarianas- de caminos cruzados, causalidades y dobles.

(Sández, 2010, p. 34) Aspiraciones superpuestas e intereses cruzados. Pero también transformaciones propias de la época. La literatura, tal como estaba planteada hasta entonces, dejaba su dominio y comenzaba a cruzarse con algunas de las expresiones de la cultura de masas, como premisa propia de los cambios socioculturales de mitad de siglo16. No es casual, en este sentido, que numerosos textos de los más prestigiosos escritores argentinos de entonces, además de los ya nombrados, hayan sido transpuestos al cine en esta época, como los de Bioy Casares (El crimen de Oribe, 1950), Borges (Días de odio, 1953; Hombre de la esquina rosada, 1962), Bianco (Las ratas, 1963), Sábato (El túnel, 1952), Denevi (Rosaura a las diez, 1958), Manauta (Las tierras blancas, 1959), Kordón (Alias Gardelito, 1961), y otros (Bottone, 1964; Couselo, 1981).

En el caso de Antín y Cortázar, el punto de encuentro se produce en el ámbito de la escritura.

En otras palabras, no coinciden en los estudios de filmación ni en las salas de montaje.

Ambos escriben. Afirman el trabajo convergente en la actividad de escritura y no en la técnica. Escribir para filmar; filmar con el ademán de la escritura. Así lo expresa Antín: "El cine es, por sobre todo, un libro. Un guión. Y lo que se hace al filmar es una transcripción a otro lenguaje, pero sin destruirlo" (Canoso, 1995, p. 14). Cortázar y Antín se juntan a escribir en pocas ocasiones; luego, entre París y Buenos Aires, viajarán cartas con proyectos, guiones, novelas, fotografías, diálogos, cintas y correcciones, tal como lo ponen de manifiesto las cartas publicadas $(2000,2012)$. En esta labor no faltan los desajustes y los desencuentros. Los destiempos de las cartas (algunas de ellas perdidas) parecen hablar de este problema. Discuten sobre los alcances culturales de los proyectos, sobre el lenguaje que van a adoptar, sobre distintos enfoques en la forma de entender las narraciones. Diferencias, también, en los roles que tienen que asumir y en las tareas que los desafían. Al respecto, Cortázar, puesto en la tarea de armar los diálogos de Circe, apunta que por momentos es un poco como si estuviera manejando un auto con los ojos vendados. Me faltan mis propias descripciones, mi propia manera de situar la cosa. Es complicado y al mismo tiempo muy fascinante, lo hago realmente con mucho gusto pero fumo como una bestia y tengo que tomar mucho ron cubano. 
(Cortázar, 2012, p. 635)17 La relación entre ambos señala también que, aunque los dos tenían interés en el lugar del otro y mostraron flexibilidad en los intercambios, Cortázar nunca se aparta demasiado de su rol de escritor. Después de todo, el ámbito elegido era el de la escritura y eran sus cuentos los que iban a ser transpuestos18. Esta modalidad produjo a la larga una especie de "dependencia" de su palabra (aunque Antín terminaba filmando según su parecer, como se puso en claro sobre todo en Intimidad de los parques) y llevó, en última instancia, a la discontinuidad de la dupla de trabajo.

\section{La primera experiencia: Circe}

El primer intercambio entre Cortázar y Antín fue en marzo de 1961. El director escribió una carta pidiéndole a Cortázar los derechos del cuento "Cartas de mamá". Éste, con cortesía, accedió dando su consentimiento. Acordaba con la suma ofrecida, avalaba al adaptador (el prestigioso guionista y narrador Arturo Cerretani) y daba su beneplácito respecto de los actores que encarnarían los personajes (María Rosa Gallo, Lautaro Murúa, Sergio Renán). Aceptó incluso el cambio de título (La cifra impar), que tenía mayor atractivo para el cine que el nombre del cuento. Esta rápida negociación muestra el grado de interés que tenía para Cortázar que uno de sus relatos fuera transpuesto a la pantalla grande. Esas pocas cartas cordiales (en las que está generalizado el uso del usted) fueron, sin embargo, toda la participación que el narrador tuvo en la película. La producción, la adaptación y el rodaje fueron realizados sin que Cortázar interviniera. La cifra impar, estrenada en noviembre de 1962, fue, en relación con la transposición literatura/ cine e independientemente del excelente resultado obtenido, un trabajo de adaptación profesional habitual, semejante a los muchos que se habían realizado en la cinematografía argentina19.

Tras esta buena experiencia y con la propuesta de un nuevo film, en el verano europeo de 1963 Cortázar y Antín se reunieron en el hotel Villa Balbi de la localidad de Sestri Levante (Italia) para realizar el guión de Circe (Imagen 1). Fue el primer encuentro de trabajo en que ambos establecieron las pautas de escritura y construyeron la estructura del relato. El desafío era para ambos: el narrador se metió de lleno en la escritura cinematográfica en la que casi no tenía experiencia y tuvo que alterar completamente su modo de escribir. Antín, por su parte, debía poner a prueba su capacidad para transformar el complejo cuento incluido en Bestiario (1951) en imágenes. Para él también era una novedad esta modalidad de trabajo de transposición.

Uno de los aspectos más curiosos de aquel encuentro es que no fue Cortázar el que marcó las guías de trabajo, tal como puede suponerse de un narrador tan reconocido, sino el director.

Con habilidad persuasiva, Antín utilizó nuevamente el recurso de contar oralmente el texto literario (como antes lo había hecho frente a sus amigos con "Cartas de mamá"), para luego dictar al escritor la estructura narrativa. Se trataba de un modo de apropiarse del relato para poder adaptarlo. Según lo recuerda Antín: Yo le dicté a Julio Cortázar una estructura. A Cortázar le contaba el cuento de él, de la misma manera como conté la película cuando mis amigos me dijeron 'vos deberías filmar una película como esa'. (...) De la misma manera le conté "Circe" a Julio Cortázar, él la escribió esa estructura y él se fue a París con esa estructura que yo le había dictado.

(Antín, comunicación personal [29 de setiembre de 2014]) Con las bases del relato cinematográfico trazadas, cada uno volvió a su ciudad para seguir elaborando el guión. Cortázar escribió los diálogos con las pautas en la mano (Cortázar escribe: "Apenas volví a París pasé a máquina tu guión, y me puse a trabajar. Anteayer por la 
noche terminé los diálogos y empecé a copiarlos" [Cortázar, 2000, p. 587]). Antín, por su lado, se dedicó a escribir las escenas y a producir el film.

El resto del trabajo siguió por correo. Las largas cartas enviadas desde París el 17 de junio, el 18 y 30 de julio de 1963 son testimonio de esta modalidad. A ellas se suma una "fonocarta", una extensa grabación de Cortázar (con una breve participación de Aurora Bernárdez) en cinta magnética en la que realizaba comentarios sobre la escritura de los diálogos de Circe. En ellas el narrador va expresando sus acuerdos y diferencias sobre el guión. En un primer momento, Cortázar indica ciertos hiatos del texto y por lo tanto determinadas oscuridades que no ayudan en construir una historia que sea relativamente amable con el espectador. "Hacia el final tu guión me resultó insuficiente. (...) Me las arreglé como pude y los diálogos salieron" (ibíd. p. 589).

En julio, por lo que se desprende de estas cartas, Antín le mandó un nuevo guión, más completo que dejó conforme a Cortázar. Las observaciones de éste son puntuales: debate sobre la edad del personaje de Mario, la "porteñización" de varios de los personajes, propone detalles para complejizar al personaje de Delia, discute el corte social con que Antín presenta los ambientes y los caracteres, aprueba los actores propuestos (Graciela Borges, Alberto Argibay, Walter Vidarte, Sergio Renán). La participación de Cortázar se limitó a estas misivas. Antín terminó de cerrar el guión con Héctor Grossi y luego rodó el film en Buenos Aires. Se estrenó el 30 de abril de 1964. Aunque Julio Cortázar siempre se mostró entusiasmado respecto de la única producción en la que participó activamente como guionista, nunca vio Circe (Canoso, 1995).

El guión de Circe planteaba varias modificaciones al relato literario de Cortázar. En el texto de Bestiario, Delia es una chica fina, silenciosa y rubia de los años 1920, cuya apariencia angelical atrapa en sus juegos al ingenuo y joven Mario. En el libro del film, en cambio, Delia una joven contemporánea al film, autoerotizada (la película tenía una toma en la que Delia, desnuda, parecía masturbarse) y provocadora. Estaba, además, construida con complejos rasgos psicológicos, una dimensión no contemplada en el cuento -la psicología no tenía demasiado lugar en la literatura fantástica-. No son personajes encerrados en los límites del barrio, como los del cuento: Delia camina por una playa de Mar del Plata y acompaña a su pretendiente en un velero por el río; Mario va a boîtes y tiene sexo. Las voces maliciosas de los vecinos del cuento mutan por las charlas entre los amigos de Mario.

Los procedimientos narrativos se radicalizan: Antín estructura el film con juegos de montaje, analepsis y cruces temporales (y no simples flashbacks), elipsis y estilemas autorales.

Esto es, Antín le sumó al relato un plus de recursos narrativos y discursivos complejos, además de una cuota de actualidad, que le dieron a la versión cinematográfica un lustre resueltamente moderno. Un tipo de modernidad que alimentaba, paralelamente, la figura de uno y de otro: Antín se consolidaba como un director sofisticado y prestigioso del cine argentino; Cortázar ensanchaba los alcances estéticos y culturales de su narrativa.

El trabajo entre Antín y Cortázar en Circe pone de manifiesto no un modo de trabajo parejo y simétrico, sino una forma de labor de escritura en la que dos actores se complementan.

Cortázar tuvo una intervención restringida: asume con entusiasmo la escritura del guión y ofrece aportes significativos a partir de uno de sus cuentos, pero no excede la escritura. En este sentido, Manuel Antín se muestra más dúctil para transitar los lugares de la literatura y del cine. La labor en conjunto entre ambos, por 
otro lado, da cuenta de los límites de la idea de una autoría individual y única. Más aún, cuestiona la suposición de una adaptación a partir de la literatura como origen. Muy por el contrario, la imagen del director contándole el cuento a su propio autor y dictándole la estructura narrativa, señala un formato de rescritura y de autoría compleja que se genera en el trabajo en colaboración.

Desencuentros y límites: Intimidad de los parques

En 1964 Manuel Antín ya tenía en marcha un nuevo proyecto: Intimidad de los parques, sobre el cuento "El ídolo de las Cícladas" (de Final del juego, de 1956)20. Incluía también una referencia hacia el relato "Continuidad de los parques" (del mismo libro). Se trataba de la tercera incursión en la literatura de Julio Cortázar, luego de La cifra impar y de Circe. La modalidad de trabajo, en este caso, fue diferente a la del film anterior. No hubo reuniones personales entre Antín y Cortázar. El director escribió una primera versión del libro cinematográfico junto a Héctor Grossi y Raymundo Calcagno y la envió a París. Con ello parecía extenderse la labor que unos meses antes los había involucrado en Circe. Sin embargo, Cortázar esta vez no tomó parte central de la escritura. Su contribución fue, a partir de un texto ya escrito, corregir y dar su parecer sobre el guión.

Entre julio y setiembre de ese año, ciertamente, Antín y Cortázar intercambiaron cartas intentando acordar sobre distintos aspectos del libro cinematográfico. Ese diálogo diferido pone de manifiesto las profundas diferencias en la concepción del film. Diferencias que no se limitan a perspectivas divergentes respecto de la estructura narrativa, los diálogos y la construcción de los personajes, entre otros, sino a contrastes conceptuales entre el director y el escritor, que se observa en un tono reticente de estas cartas.

El punto principal que abría esas diferencias se encontraba el plano fantástico, que es evadido en el guión cinematográfico. El cuento "El ídolo de las Cícladas" se centra en un descubrimiento de una estatuilla ancestral que despierta sobrenaturalmente extraños deseos en los personajes. En el relato, Somoza se transforma por efecto de fuerzas extrañas en una especie de sacerdote de una deidad antigua (Haghesa) que lo empuja a atacar a Morand con el fin de ofrecer un sacrificio. Esta acción está apuntalada por una segunda línea argumental: un triángulo que empuja los celos y las desconfianzas entre Morand, Somoza y Thérèse. En Intimidad de los parques, en cambio, las relaciones entre los tres y sus complejidades psicológicas prevalecen sobre cualquier aspecto fantástico. Antín propone, en este sentido, llevar un plano fantástico (un género propio de décadas previas) para actualizarlo en un tipo de relato cinematográfico realista y moderno. La propuesta del guión estaba lejos de satisfacer a Cortázar, que señalaba las diferencias en el concepto de magia entre ambos: La noción de magia es distinta en vos y en mí, no cabe duda, pero el hecho de que notes esa carencia prueba creo- que has sido sensible al enorme desajuste que hay entre las razones del drama y su espectacular desenlace a hachazo limpio (...) Te has negado a admitir el lado demoníaco del cuento. Y sin eso, creeme, no hay cuento. Más todavía: si querés hacer una película esencialmente psicológica-que es tu fuerte, es evidentedeberías buscar las ideas por otro lado. Un cuento de Moravia, digamos, te daría muchos más elementos que un cuento mío. O uno de Goytisolo, o de Salinger: cualquiera de los que no salen de la realidad diurna, y ahondan en ella admirablemente. Mis cuentos (...) presuponen inalienablemente una aceptación de fuerzas ocultas.

(Cortázar, 2012, p. 537) Hay que tener en cuenta, para complementar esta observación, la distancia que Cortázar marcaba en esta misma carta de julio de 1964 respecto de lo que él señalaba desdeñosamente como "los novelistas del cine" (p. 538), Antonioni y Fellini, y, en cambio, el aprecio hacia los filmes de corte surrealista 
o absurdo que destaca en otros momentos (Cocteau, Buñuel, los hermanos Marx). Estaba poniendo en claro, de este modo, el tipo discursivo más adecuado para sus relatos fantásticos.

El desacuerdo se extiende a las locaciones elegidas y a las modificaciones que se tuvieron que hacer en consecuencia. Manuel Antín había obtenido financiamiento de un productor peruano, por lo cual optó por cambiar las islas del Egeo por las ruinas de Machu Picchu.

En otras palabras, debía transformar el mármol en piedra, convertir una antigua cultura mediterránea en una precolombina. Este aspecto contrariaba a Cortázar, quien le apuntaba que los pueblos andinos no se habían hecho conocidos por sus sacrificios sangrientos, por lo que se le restaba verosimilitud al relato. Bajo el mismo punto de vista, incluso, objetaba la música propuesta en el guión: No me gusta mucho lo de las victrolas y los discos que se ponen a sonar cuando nos conviene a nosotros. Yo creo que la banda sonora de esta película debería ser muy especial, y si te interesan mis ideas al respecto, te enviaría llegado el momento una cinta grabada con algunas muestras del tipo de música (modernísima, abstractísima, primitivísima, pero en todo caso sin ninguna melodía convencional) que me parece adecuada. (...) La música concreta hace cosas magníficas en este terreno. En realidad debería oírse "la música de Haghesa", o sea que no será una música para los oídos occidentales.

(Cortázar, 2012, pp. 546-547)21 El otro eje de discusión no es nuevo y había sido motivos de diferencias entre los dos desde años atrás. Las propuestas de Antín para una película parecen ser demasiado rebuscadas u oscuras para Cortázar -para lo que debía ser el cine según Cortázar-, aspecto que va desde el título (Intimidad de los parques o el alternativo La infiel) hasta la inclusión del cuento "Continuidad de los parques" en el guión. Este texto no aparece como una alusión lejana, sino de manera explícita: el personaje de Héctor (Francisco Rabal) tiene en sus manos un ejemplar de Final del juego, y acostado en la cama, lee en voz alta a su pareja Teresa (Dora Baret) el relato de Cortázar, mientras se intercalan imágenes ficcionales de él. La idea del relato dentro del relato era tan explícita y la referencia era tan directa que fue impugnada por el narrador: Qué querés, no he terminado de entender la intercalación de "Continuidad de los parques" en la forma que vos lo intercalás. (...) La mención de mi nombre en el diálogo la rechazo de plano. (...) esa lectura de algunos pasajes de "Continuidad...", así sueltos no tienen el menor sentido.

(Cortázar, 2012, p. 546) Por fuera de la opinión de Cortázar, la fusión de ambas narraciones en el guión era un hallazgo. Con la inclusión de "Continuidad de los parques" Antín reunía uno y otro relato tomando como eje el triángulo amoroso que aunque presente no está en el primer plano de los textos de Cortázar. Con esta breve inserción, además, el guión incorporaba el único trazo manifiestamente fantástico, no ya en la figura de una posesión y un rito ancestral, sino en el juego de analepsis y prolepsis que rompen la continuación cronológica del relato.

Más que en sus filmes anteriores, es Intimidad el más audaz en relación con una ruptura de las líneas temporales. En este sentido, "Continuidad..." le ofrece al guión un aspecto de innovación, y sin él se hubiera reiterado sobre una estructura semejante a La cifra impar. David Obiña (1994) advierte el valor de la inclusión de "Continuidad..." en el film: Hasta aquí, Antín había trabajado sobre dos series paralelas que se comunicaban en un vaivén de pasajes. Ahora, la dimensión de futuro no viene a agregar una tercera serie sino que tiende a fusionarlas, diluyendo el centro. (...) Si bien el relato se enuncia desde el presente, permanentemente quiebra la 
dirección hacia delante para fluir en todas direcciones y construir una serie múltiple, hecha de fragmentos de distinta temporalidad: una "narración acrónica", en donde el tiempo no resulta una especificidad diferencial.

(Oubiña, 1994, pp. 25-26) Con esa imagen de un libro como elemento modernizador del film Antín insistía, además, en aliarse a la literatura como una zona cultural que motorizaba su cine.

Aunque una segunda versión del guión obtuvo la venia de Cortázar, éste nunca expresó su completa anuencia con Intimidad de los parques. Pensaba, según se entiende de sus cartas, que la propuesta escrita se arriesgaba sobre elementos demasiado difíciles de resolver estética y técnicamente. Como le señaló el 19 de agosto de 1964: Sigo creyendo que es tu obra más comprometida, más peligrosamente resbaladiza.

Un error, y nos vamos al agua. La cosa es demasiado extrema, toca terrenos demasiado hondos como para tolerar un margen de aciertos relativos. Clavás la flecha en el medio del blando o perdés todo.

(Cortázar, 2012, p. 555) La apuesta de Antín era ciertamente osada y esos riesgos le jugaron en contra. Filmó en Perú durante dos semanas sin poder ver lo que se realizaba día a día por problemas técnicos.

Cuando retornó a Buenos Aires para revelar el film, descubrió que el 40 por ciento del celuloide tenía estática por efecto de la altura y de la alta temperatura de la sierra peruana.

Tuvo que montar la película con el material restante. El resultado dejó inconforme al director y al mismo Julio Cortázar, que, sin embargo, no hizo comentarios al respecto.

"Se cumplió la profecía de Cortázar" -señala resignado Antín- "cuando advirtió que un mínimo inconveniente podía echar a perder una película excelente" (Sández, 2010, p. 78).

\section{Conclusiones}

En 1965, Antín produjo su siguiente película, Castigo al traidor. Se basaba en el cuento "Encuentro con el traidor" del narrador paraguayo Augusto Roa Bastos. Éste era un asiduo colaborador de libros cinematográficos (había trabajado con Armando Bo y Lautaro Murúa), pero el director optó por trabajar de otro modo: compró los derechos del texto, contrató a un colaborador (Andrés Lizarraga) y, junto a éste, elaboró el guión. Con ello, y acaso desanimado por la difícil experiencia de Intimidad de los parques, volvía a escribir de la misma forma en que lo había realizado en su primer film, que era el modo habitual de adaptación.

Por otro lado, luego de Intimidad de los parques, la relación personal entre Antín y Cortázar se fue debilitando. El vínculo epistolar entre los dos se mantuvo hasta 1975, aunque con escasos intercambios de cartas. El narrador alcanzó la cumbre de su fama internacional durante la década de 1960. Fueron años en que también algunos de los directores de cine más prestigiosos del momento apelaron a sus relatos para ser transpuestos libremente al cine, como Michelangelo Antonioni (Blow-up, 1966, sobre "Las babas del diablo") y Jean-Luc Godard (Weekend, 1967, sobre "La autopista del sur"), datos que señalan no sólo un vínculo continuo de su literatura con la pantalla grande, sino también la sintonía de su narrativa con la cultura de esta década.

La dupla de trabajo Antín/ Cortázar revela las posibilidades de convergencia y sinergia entre la literatura y el cine en Argentina. Pero también sus límites. Por un lado, y desde un punto sociológico, la sociedad entre ambos 
ámbitos pone de manifiesto cierta acreditación para una parte emergente del cine que le ofrece un nuevo escalafón en el campo cultural. En este sentido, esta alianza es uno de los cruces productivos que pusieron en marcha y renovaron a la pantalla grande en el paso de los años 1950 a los 1960. En la misma perspectiva, le dio a una literatura prestigiosa y consolidada pero limitada en sus alcances sociales, la posibilidad de abrirse hacia la cultura de masas. En contigüidad, la sociedad entre el director y el narrador señala un fortalecimiento de sus figuras respectivas.

Luego de la trilogía cortazariana, Manuel Antín (en sólo cuatro años), emerge como uno de los cineastas más reconocidos de cine, efecto de su apego a un escritor que crecía en reconocimiento y prestigio. Cortázar, por su lado, tiene con Antín sus primeros acercamientos al cine y, por lo tanto, a un nuevo medio de expresión que acompaña y les otorga nuevos valores a sus textos.

Por otra parte, la colaboración inédita entre estas dos figuras se produce alrededor de dos núcleos. Por un lado, de la escritura. Ambos se reúnen no en los estudios sino para escribir los libros cinematográficos de dos filmes. Es la escritura, como labor con sus propias especificidades, la que los aglutina como actores culturales. Por el otro, ambos coinciden en su atractivo por un modo de expresión moderno. Uno y otro están atraídos por formas novedosas de expresión con palabras, imágenes y sonidos que rehúyen del clasicismo en el cine y en la literatura.

Antín y Cortázar fueron una sociedad virtuosa aunque desencontrada. Las visiones culturales divergentes de uno y de otro alimentaron sus diferencias. Sin embargo, Circe e Intimidad de los parques, registros de una avanzada cultural sofisticada y moderna, y muestras de experiencias de trabajo excepcionales, dan cuenta de las potencialidades del cruce entre distintas zonas culturales, y del enriquecimiento de la producción bajo las luces de la escritura en colaboración.

\section{Notas}

1. Las fechas informadas son las de la producción del film y no la de su estreno.

En 1962, además, Antín filmó Los venerables todos a partir de una novela escrita por él mismo en 1958. Esta película fue presentada en los prestigiosos festivales de Cannes y de Sestri Levante y obtuvo excelentes críticas, pero nunca fue estrenada comercialmente en Argentina, debido a la calificación "B" del Instituto Nacional de Cinematografía, que le obstaculizaba el acceso a su estreno y a los premios anuales. Recién pudo ser vista públicamente cuando el programa Función Privada de ATC (Canal 7) la emitió en 1984 (Sández, 2010). Por otro lado, el único ejemplar de la novela Los venerables todos fue extraviada.

Antín se la envió a Julio Cortázar para que la leyera, pero éste la olvidó en un hotel de Viena (Antín, comunicación personal [29 de setiembre de 2014]).

En esta investigación se utiliza el concepto de transposición por la de adaptación, de acuerdo a la propuesta de Sergio Wolf (2001), quien encuentra en el primer término una descripción más adecuada y compleja de aquello que significan las relaciones entre literatura y cine: "Transposición designa la idea de traslado, pero también la de transplante, de poner algo en otro sitio, de extirpar ciertos modelos, pero pensando en otro registro o sistema" (p. 16). 
2. Sobre las relaciones de la literatura y el cine, ver el estudio de Miguel Couselo, "Literatura argentina y cine nacional" (1981).

Como dan cuenta estos nombres, hasta los años 1950 los escritores que colaboraron como guionistas cinematográficos fueron aquellos que tenían un vínculo político-cultural con expresiones populares, como el tango y el teatro.

3. Uno de los antecedentes más cercanos de este tipo de asociaciones es el film El túnel (1952) que el director León Klimovsky escribió junto a Ernesto Sábato, autor de la novela homónima. Se trata, no obstante, de un caso aislado. Sábato volvió a escribir sólo ocasionalmente para el cine, aunque algunos de sus textos fueron transpuestos a la pantalla grande sin su intervención directa, como El poder de las tinieblas (1979, dirigida por su hijo Mario Sábato), en base a Informe sobre ciegos.

4. Ambos escritores, además, se convirtieron en directores de cine en los años siguientes. Duras realizó películas notables, como Nathalie Granger (1972), India Song (1975) y Le camion (1977). Robbe- Grillet, por su parte, llegó a escribir y dirigir una decena de filmes, entre otros L'immortelle (1963), Trans-Europ-Express (1966) y L'homme qui ment (1968).

5. Esta lectura canónica estaba orientada por un criterio político. Era una manera de enrostrar al peronismo sus políticas sobre cine en la imagen de una maquinaria propagandística y reiterativa. En Cine y peronismo (2009), Clara Kriger advierte que a partir de la Historia del cine argentino de Domingo di Núbila, publicada en 1959, se imprimió un modo de ver el cine de los años previos, perspectiva que fue reiterada por estudios posteriores. Kriger señala además que en el corpus de filmes producidos durante el gobierno peronista sólo excepcionalmente aparecen las imágenes de Perón y de Evita, y que, en cambio, la acción del Estado estaba escenificado a partir de sus efectos beneficiosos (mejoras en hospitales, orfanatos, cárceles, políticas de protección a las mujeres, niños y desprotegidos, etc.).

6. Torre Nilsson fue asistente en numerosas realizaciones de los años 1940 antes de convertirse en director. La mayoría de esas participaciones fueron en producciones de su padre, Leopoldo Torres Ríos.

7. Algunos de los ejemplos de estos aspectos que ofrece Claudio España (1977) son Barrio Gris (1954, dirigida por Mario Soffici), Danza del fuego (1948, dirigida por Daniel Tinayre), El túnel (1952, dirigida por León Klimovsky), Días de odio y La casa del ángel (1953 y 1956, dirigidas por Leopoldo Torre Nilsson).

8. Se trata de los libros de poemas La torre de la mañana (1945), Sirena y espiral (1950) y Poemas para dos ciudades (1952). Todos ellos fueron escritos antes de iniciar su actividad en el cine.

La vocación literaria de Antín es semejante a la de Leopoldo Torre Nilsson, que se consideraba un escritor frustrado. Publicó varios títulos, como los poemarios Tránsito de la gota de agua (1947) y Contar pérdidas (1977), el volumen de relatos Entre sajones y el arrabal (1967) y las novelas El derrotado (1964) y Jorge, el nadador (1978).

9. Según la entrevista de María Lyda Canoso, incluida en el libro que editó el mismo Antín, Cartas de cine (1995), en "1956 o 1957" se encontró con el volumen Bestiario en la biblioteca de un amigo (p. 14). El mismo dato reitera en el libro Generaciones 60/90 de Fernando M. Peña: "Un día fui a visitar a un amigo profesor de 
literatura y mientras lo esperaba, empecé a buscar libros en su biblioteca hasta que descolgué uno que se llamaba Bestiario. Cuando vino le pregunté: 'Che, ¿Quién es Cortázar?, 'Ah, no sé, me lo mandó la editorial'” (2003, p. 32).

10. Otra vez, es necesario destacar la cercanía de la postura de Antín con Leopoldo Torre Nilsson. En 1978, éste decía: "No me imagino al director cinematográfico como un hombre que sabe de lentes o de moviolas y cámaras, sino como un narrador de destinos con un procedimiento contemporáneo. El cineasta debe ser un novelista (...) Sé que soy dos personas: una que escribe y otra que filma. Me gustaría que las dos se juntaras y presiento que en mi carrera se deben haber juntado. Cinematográficamente, los libros de mis films son escritos en última instancia por mí. Con un equipo, es claro, pero considero que un escritor debe escribir. Un director que no escribe es un director rengo, porque está dependiendo de la función específicamente creativa (...)" (cit. en Couselo, 1981, p. 618).

11. La carta tiene la fecha del 7 de enero de 1964.

12. Cortázar estuvo ligado a la revista Sur durante la década de 1940.

13. La única película realmente exitosa de Antín fue Don Segundo Sombra (1969), que posee una propuesta estética distinta a la de sus primeros cinco filmes. Ver al respecto de este film el estudio de David Oubiña (1994).

14. Así lo señalan las cartas de Cortázar (2012; Canoso, 1995). Buñuel estuvo a punto de realizar una versión cinematográfica del cuento "Las ménades". El 30 de noviembre de 1962, el narrador le envió una carta a Buñuel, transmitiéndole su entusiasmo por ese proyecto y proponiéndole un precio para venderle los derechos de ese relato. Por un problema presupuestario, sin embargo, la película nunca llegó a filmarse.

En sus cartas, además, señala preferencias y disgustos por el cine. Le gustaba Godard, Resnais, Welles, Polanski, pero lo aburría Fellini, Hitchcock, Robbe-Grillet y Antonioni (aunque este último filmaría a partir de uno de los cuentos de Cortázar su película más difundida, Blow-up [1966]).

15. La novela Divertimento que entonces Cortázar ofreció a Antín había sido escrita en 1949 y recién fue publicada luego de la muerte del escritor, en 1986.

16. Ver los cambios en los procesos culturales de esta época en los textos de Oscar Terán (1991), Silvia Sigal (1991) y Claudia Gilman (2003).

17. Estas palabras son parte de un mensaje en cinta magnética que Cortázar mandó a Antín con los comentarios del guión y los diálogos de Circe. El envío está fechado el 17 de junio de 1963.

18. Téngase en cuenta, además, que este momento es consagratorio para Cortázar. En octubre de 1963 publicó la novela Rayuela que lo convirtió en un afamado escritor internacional.

19. Aunque con un público limitado, la película La cifra impar fue muy bien recibida por la crítica (Oubiña, 1994; Sández, 2010). Obtuvo el $5^{\circ}$ premio al mejor film por parte del Instituto Nacional de Cinematografía y varios reconocimientos de la Asociación de Cronistas Cinematográficos. Fue, además, exhibida en los festivales de cine de Venecia y de Sestri Levante. 
El rodaje de La cifra impar en París (lo que ya era una novedad para el cine argentino) dio la oportunidad, además, de que Antín y Cortázar se conocieran personalmente. Así lo recuerda el director: "Nos vimos por primera vez en un encuentro memorable, en la place du Fürstenberg, en París, cuando viajamos para filmar. No lo olvido nunca, yo estaba tirado en la vereda, con la cámara al ras del suelo, haciendo una toma de María Rosa Gallo, la Laura de la película, que en esa escena miraba vidrieras y galerías abstraída del mundo. En un momento detecté unos pies al lado mío, levanté la mirada y me encontré con los ojos tan especiales de Julio Cortázar. Era altísimo, pero visto desde el suelo parecía un gigante" (Sández, 2010, p. 35).

Por otro lado, Cortázar vio en Buenos Aires La cifra impar en una función privada antes del estreno, junto al director: "Permanecimos en silencio durante la exhibición hasta que llegó esa escena en la que Luis (Lautaro Murúa) le dice a Doña Lía (Milagros de la Vega) 'Mamá, Laura es vos'. Justo en ese momento, Cortázar me palmeó el hombro y me dijo ‘¡Pibe, gracias, entendí mi cuento!’” (Sández, 2010, p. 58).

20. El libro Final del juego, que luego se convertiría en un clásico de Cortázar, se publicó inicialmente en México en 1956. Luego del suceso de Rayuela, el sello Sudamericana lo reeditó en Buenos Aires en 1964, incorporando nuevos relatos.

21. Carta del 4 de agosto de 1964.

Bibliografía

Bottone, M. (1964). La literatura argentina y el cine. Santa Fe: Universidad Nacional del Litoral.

Canoso, M. L. (1995). Cartas de cine. Julio Cortázar a Manuel Antín (1961-1975). Buenos Aires: s/d.

Cortázar, J. (1951). Bestiario. Buenos Aires: Sudamericana.

Cortázar, J. (1959). Las armas secretas. Buenos Aires: Sudamericana.

Cortázar, J. (1964). Final del juego. Buenos Aires: Sudamericana.

Cortázar, J. (2000). Cartas I. 1937-1963. Buenos Aires: Alfaguara.

Cortázar, J. (2012). Cartas 1955-1964. Buenos Aires: Alfaguara.

Couselo, J. (1981). Literatura argentina y cine nacional. En Capítulo. La historia de la literatura argentina (pp. 601-624), 96. Buenos Aires: CEAL.

España, C. (1997, enero- diciembre). Emergencia y tensiones en el cine argentino de los años cincuenta. Nuevo Texto Crítico (19-20), 45-73.

España, C. (dir.) (2005). Cine argentino. Modernidad y vanguardias 1957-1983. Buenos Aires: Fondo Nacional de las Artes.

Faulstich, W. y Korte, H. (1995). Cien años de cine. Vol.3: 1945-1960. Hacia una búsqueda de los valores. México: Siglo XXI. 
Gilman, C. (2003). Entre la pluma y el fusil. Debates y dilemas del escritor revolucionario en América Latina. Buenos Aires: Siglo XXI.

Kriger, C. (2009). Cine y peronismo. El estado en escena. Buenos Aires: Siglo XXI.

Lafon, M. y Peeters, B. (2008). Escribir en colaboración. Historias de dúos de escritores. Rosario: Beatriz Viterbo.

Neifert, A. (2005). Del papel al celuloide. Escritores argentinos en el cine. Buenos Aires: La Crujía.

Oubiña, D. (1994). Manuel Antín. Buenos Aires: CEAL.

Oubiña, D. (2011). El silencio y sus bordes. Modos de lo extremo en la literatura y el cine. Buenos Aires: Fondo de Cultura Económica.

Peña, F. M. (comp.) (2003). Generaciones 60/90. Cine argentino independiente. Buenos Aires: MALBA.

Peña, F. M. (2012). Cien años de cine argentino. Buenos Aires: Biblos.

Queirolo, G. (2009). Victoria Ocampo: Cruces entre feminismo, clase y elite intelectual. Clío \& Asociados (13), 135-159. En Memoria Académica. Disponible en:

http://www.fuentesmemoria.fahce.unlp.edu.ar/art_revistas/pr.4628/pr.4628.pdf Sández, M. (2010). El cine de Manuel. Un recorrido sobre la obra de Manuel Antín. Buenos Aires: Capital Intelectual.

Sánchez Noriega, J. L. (2000). De la literatura al cine. Teoría y análisis de la adaptación. Barcelona: Paidós.

Sigal, S. (1991). Intelectuales y poder en la década del sesenta. Buenos Aires: Puntosur.

Stam, R. (2001). Teorías del cine. Una introducción. Barcelona: Paidós.

Terán, O. (1991). Nuestros años sesentas. La formación de la nueva izquierda intelectual en Argentina 19561966. Buenos Aires: Puntosur.

Wolf, S. (2001). Cine/ Literatura. Ritos de pasaje. Buenos Aires: Paidós.

Películas

Harding, A. y Schon, R. (Productores), Antín, M. (Director). (1961). La cifra impar [Película]. Argentina: Cinematográfica Novus.

Antín, M. (Productor), Antín, M. (Director). (1963). Circe [Película]. Argentina: Producciones Manuel Antín.

Antín, M. e Industria Peruana Cinematográfica (Productores), Antín, M. (Director). (1964). Intimidad de los parques [Película]. Argentina/ Perú.

Abstract: 
This paper examines the mutual cooperation between the filmmaker Manuel Antín and the writer Julio Cortázar since 1963 to 1965. In those years, they worked on writing scripts for the films Circe and Intimidad de los parques. The link both artists built on personal encounters and through letters reveals an unprecedented work in Argentine cinema. Furthermore, the relationship between these two figures shows a change in the association between cinema and literature within the cultural field. In this sense, during the 1960 decade, both literature and cinema synergistically tie relationships that enhance their socio-cultural length.

Key words:

argentine cinema - argentine literature - Manuel Antín - Julio Cortázar - writing - teamwork.

\section{Resumo:}

Este artigo estuda a relação de colaboração mútua que mantiveram o cineasta Manuel Antín e o narrador Julio Cortázar entre 1963 e 1965. Durante este tempo, ambos trabalharam na redação de roteiros dos filmes Circe e Intimidad de los parques. O vínculo que ambos construíram em seus encontros pessoais, e através de cartas, revela um modo de trabalho inédito no cinema argentino em torno da escrita cinematográfica. Além disso, a relação entre estas duas figuras dá conta de uma mudança nos vínculos entre o cinema e a literatura dentro do campo cultural. Neste sentido, durante os anos 1960, ambos os espaços traçam laços sinérgicos que melhoram sua dimensão sociocultural.

Palavras chave:

cinema argentino - literatura argentina - Manuel Antín - Julio Cortázar - escrita - colaboração.

Antín / Cortázar: cruces y destiempos entre la escritura y el cine fue publicado de la página 89 a página106 en Cuadernos del Centro de Estudios de Diseño y Comunicación № 61 